\title{
Terrestrial Bird Migration and West Nile Virus Circulation, United States
}

\author{
Daniele Swetnam, Steven G. Widen, Thomas G. Wood, Martin Reyna, \\ Lauren Wilkerson, Mustapha Debboun, Dreda A. Symonds, Daniel G. Mead, \\ Barry J. Beaty, Hilda Guzman, Robert B. Tesh, Alan D.T. Barrett
}

Host migration and emerging pathogens are strongly associated, especially with regard to zoonotic diseases. West Nile virus (WNV), a mosquitoborne pathogen capable of causing severe, sometimes fatal, neuroinvasive disease in humans, is maintained in highly mobile avian hosts. Using phylogeographic approaches, we investigated the relationship between WNV circulation in the United States and the flight paths of terrestrial birds. We demonstrated southward migration of WNV in the eastern flyway and northward migration in the central flyway, which is consistent with the looped flight paths of many terrestrial birds. We also identified 3 optimal locations for targeted WNV surveillance campaigns in the United States-Illinois, New York, and Texas. These results illustrate the value of multidisciplinary approaches to surveillance of infectious diseases, especially zoonotic diseases.

$\mathrm{W}$ est Nile virus (WNV) is a mosquitoborne virus that can cause severe and even fatal disease in humans. After WNV introduction into New York, NY, USA, its geographic range expanded quickly, reaching the West Coast in 2003. Previous studies have shown that the spread of WNV occurred faster than could be explained by contiguous diffusion (1-4) and demonstrated that its expansion occurred heterogeneously, consisting of contiguous diffusion and long distance translocations $(2,5)$. Since then, phylogeographic studies have reported frequent mixing of WNV strains from local and distant locations. The most notable exception is California, where several genetic studies have shown limited movement into and out of the state $(6,7)$.

Author affiliations: University of California at Davis, Davis, California, USA (D. Swetnam); University of Texas Medical Branch, Galveston, Texas, USA (D. Swetnam, S.G. Widen, T.G. Wood, H. Guzman, R.B. Tesh, A.D.T. Barrett); Harris County Public Health, Houston, Texas, USA (M. Reyna, L. Wilkerson, M. Debboun); Chesapeake Mosquito Control Commission, Chesapeake, Virginia, USA (D.A. Symonds); University of Georgia, Athens, Georgia, USA (D.G. Mead); Colorado State University, Fort Collins, Colorado, USA (B.J. Beaty)

DOI: https://doi.org/10.3201/eid2412.180382
The rapid expansion of WNV in the United States probably cannot be attributed to the movement of humans because humans are dead-end hosts. However, in nature, WNV is maintained in an enzootic transmission cycle involving mosquito vectors and highly mobile avian reservoirs. Hyalomma marginatum ticks have also been implicated in the transmission of WNV (8).

Although evidence of WNV infection has been identified in many species of birds, deaths and disease among birds vary greatly, ranging from asymptomatic to fatal infections; peak viremia potentially reaches $>10^{12} \mathrm{PFU} / \mathrm{mL}$ (9). WNV RNA has been detected in bird spleen and kidneys as long as 36 weeks after infection (10) and in brains of Nestor notabilis kea up to 72 months after infection (11).

Although phylogenetic evidence of geographic clustering by location is limited, a recent study reported that WNV isolates clustered according to avian flyway (12). Because birds are the primary reservoirs for $\mathrm{WNV}$, this finding was not surprising, but it is relevant because bird migration has also been implicated in the movement of influenza A virus (13), Borrelia burgdorferi (Lyme disease agent) (14), other pathogenic organisms (1), and even invasive invertebrate organisms (15). Several serologic studies (e.g., ELISA, plaque reduction neutralization test) have been used to determine the direction of WNV movement within the Atlantic, Mississippi, and Pacific flyways and demonstrated WNV in birds migrating southward, whereas evidence of the virus in birds during northward migration is limited $(16,17)$.

Studies of virus movement associated with avian hosts in the United States have concentrated on the migration of waterfowl and excluded terrestrial birds, largely because the migratory patterns of waterfowl have been thoroughly characterized by banding studies. However, passerine birds, the primary reservoir for $\mathrm{WNV}$, are terrestrial birds, not waterfowl. Terrestrial birds and waterfowl fly along similar but distinct flyways. Although waterfowl follow regular paths bounded by mountains and rivers, terrestrial birds often follow looped routes that enable them to maximize tail winds, avoid head winds, and correlate with seasonal fluctuations in food availability $(18,19)$. Although looped migration paths have been described for several 
species of birds (Selasphorus rufus hummingbirds [20], Circus aeruginosus western marsh harriers [21], Falco eleonorae Eleonora's falcons [22], Cuculus canorus common cuckoos [23]), the general flyways of terrestrial birds have been inadequately studied. However, in 2014, La Sorte et al. provided a general description of terrestrial bird flyways in North America (18). They defined 3 flyways: the single distinct Western flyway and 2 overlapping flyways, the Central and Eastern flyways. A similar 3-flyways system (Pacific, Central, and Atlantic flyways) has been described for waterfowl (24); however, most studies have relied on the more common 4-flyways system (Pacific, Central, Mississippi, and Atlantic flyways). In this study, we used phylogeographic approaches to investigate the relationship between WNV circulation in the United States and the flight paths of terrestrial birds.

\section{Methods}

\section{Generation of Alignments}

We identified all unique sequences of natural and laboratory WNV strains by using the Virus Variation Resource (25). Virus sequences meeting the following criteria were included in this study: 1) the nucleotide sequence spanned the complete open reading frame, 2) the sequence was derived from natural isolates and not laboratory strains, 3) the sequence was unique (i.e., all sequences differed by $\geq 1 \mathrm{nt}$ ), and 4) the sequence contained no degenerate nucleotides. All sequences were manually aligned in BioEdit version 7.1.3 (http://www.mbio.ncsu.edu/BioEdit/bioedit.html) or MEGA7 (https://www.megasoftware.net/), and noncoding regions were removed when necessary (i.e., the open reading frame was used for analyses).

\section{Isolation of Viral RNA and Next-Generation Sequencing}

We obtained additional WNV isolates from the World Reference Center for Emerging Viruses and Arboviruses at the University of Texas Medical Branch at Galveston (Galveston, TX, USA) (26). Isolates were originally collected from Virginia, Georgia, Texas, and Colorado. We extracted viral RNA from the supernatant of infected Vero cells by using a QIAamp Viral RNA Mini Kit (QIAGEN, Germantown, MD, USA) according to the manufacturer's instructions.
We generated libraries with a TruSeq RNA version 2 kit (Illumina, San Diego, CA, USA) and samples sequenced by the University of Texas Medical Branch at Galveston Next Generation Sequencing Core on an Illumina $1500 \mathrm{Hi}-\mathrm{Seq}$ platform. Adaptor sequences and poor quality reads (Q score $<20)$ were removed with Trimmomatic (27). Reads were aligned with Bowtie2 (28) under the sensitive local parameter against the prototypical strain of WNV (NY99 flamingo 382-99, GenBank accession no. AF196835). Consensus sequences were generated by using SAMtools (29).

\section{Phylogeny}

To evaluate temporal structure, we generated a time-naive phylogeny (i.e., a maximum-likelihood phylogeny) to enable determination of the patristic distance between all isolates on the phylogeny. We generated maximum-likelihood trees with RAxML-HPC Black Box on Cyberinfrastructure for Phylogenetic Research version 3.3 (30) and determined automatic halting by bootstrapping. We determined the root-to-tip distance, which is a phylogenetic measure of genetic distance, for each isolate of the maximum-likelihood phylogenies by using TempEst (formerly Path-o-gen) (31). We evaluated the correlation (Pearson method) between root-to-tip distance and collection date in R (https://www.r-project.org/).

We used a Bayesian Markov chain Monte Carlo (MCMC) approach to infer phylogeographic relationships and selected the most appropriate phylogenetic model by using standard path sampling and stepping-stone approaches. XML files were generated in BEAUti version 1.8.3 or 1.8.4 and run with BEAST version 1.8.4 (32) on Cyberinfrastructure for Phylogenetic Research (30). We used the $\mathrm{GTR}+\Gamma+\mathrm{I}$ (general time reversible with gamma rate distribution and invariable sites) model to infer nucleotide substitution frequencies, an uncorrelated lognormal clock model to infer the mutation rate, and a Bayesian Skyline tree prior to model changes in population size. The evolution rate mean was restricted to $10^{-4}$ through $9 \times 10^{-4}$ substitutions/site/year, consistent with previously reported rates for WNV evolution $(7,33)$.

We ran trees with an MCMC length of 100 million and sampled every 5,000 steps. Log files were reviewed in Tracer (http://tree.bio.ed.ac.uk/software/tracer/) to determine burn-in, which ranged from $5 \%$ through $10 \%$. We ran

\begin{tabular}{|c|c|c|c|c|c|c|c|c|c|c|c|c|c|c|c|c|}
\hline Location & 1999 & 2000 & 2001 & 2002 & 2003 & 2004 & 2005 & 2006 & 2007 & 2008 & 2009 & 2010 & 2011 & 2012 & 2013 & 2014 \\
\hline$\overline{N Y}$ & $x$ & & $x$ & $x$ & $x$ & $x$ & $x$ & & $x$ & $x$ & & & $x$ & & & \\
\hline VA & & $x$ & $x$ & $x$ & $x$ & $x$ & $x$ & $x$ & $x$ & $x$ & $x$ & $x$ & & & & \\
\hline GA & & & $x$ & $x$ & & $x$ & $x$ & & $x$ & $x$ & $x$ & & & & & \\
\hline IL & & & & $x$ & $x$ & $x$ & $x$ & $x$ & $x$ & & & & & & & \\
\hline $\mathrm{TX}$ & & & & $x$ & $x$ & & $x$ & $x$ & $x$ & & $x$ & $x$ & $x$ & $x$ & $x$ & $x$ \\
\hline $\mathrm{CO}$ & & & & $x$ & $x$ & $x$ & & $x$ & $x$ & $x$ & $x$ & & & & & \\
\hline ND & & & & $x$ & $x$ & $x$ & $x$ & $x$ & & $x$ & $x$ & & & & & \\
\hline SD & & & & & $x$ & $x$ & $x$ & $x$ & $x$ & $x$ & $x$ & & & & & \\
\hline
\end{tabular}




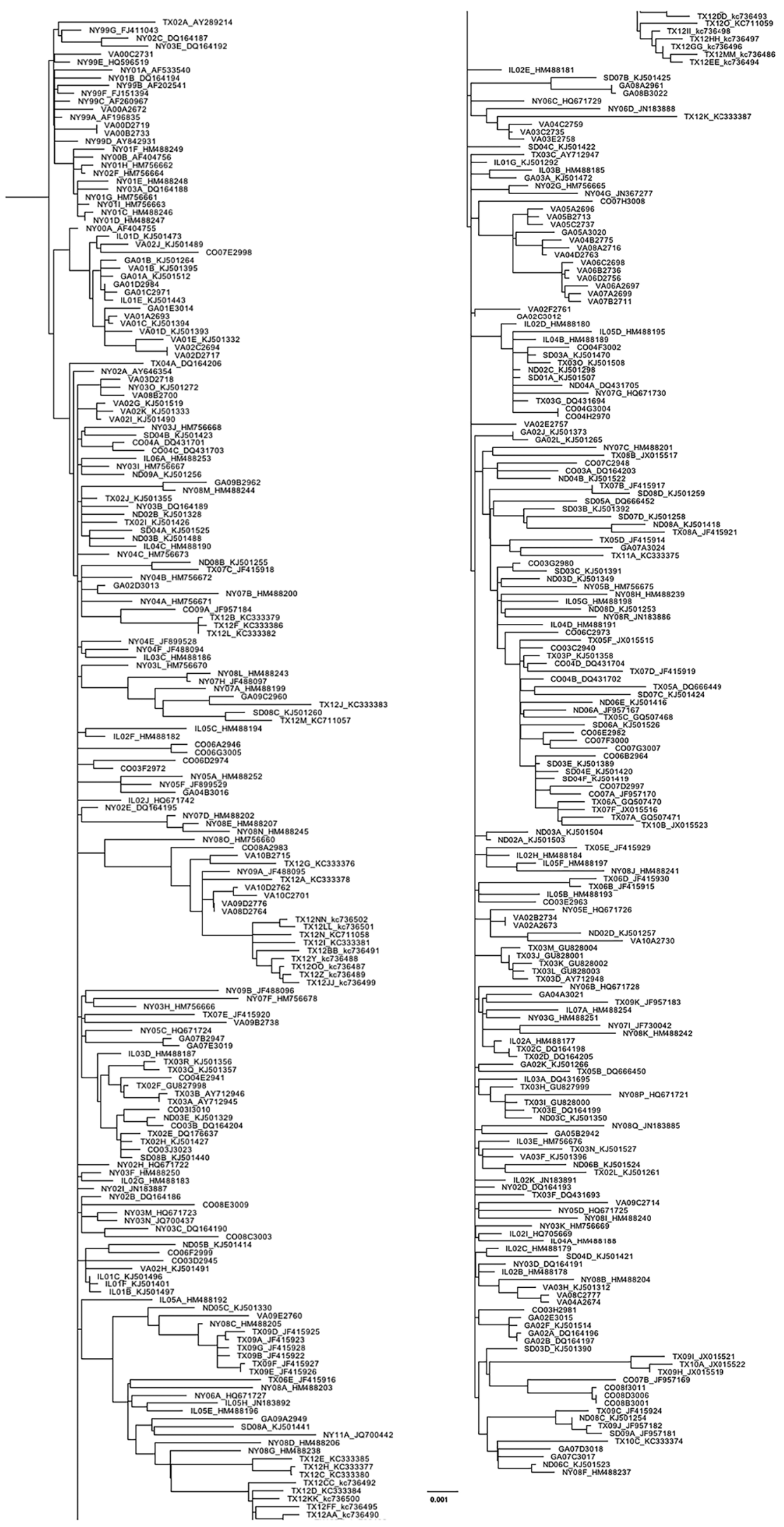

Figure 1. Maximum-likelihood phylogeny generated with all West Nile virus sequences from New York, Virginia, Georgia, Illinois, North Dakota, South Dakota, Texas, and Colorado $(n=379)$ in study of terrestrial bird migration and West Nile virus circulation, United States. Sequence names include the 2-letter state abbreviation to indicate the origin of isolation, followed by the year. Multiple isolates collected from the same state within the same year are differentiated by letter. GenBank accession numbers are provided for all taxa that were not sequenced in this study. Scale bar indicates nucleotide substitutions per site. 


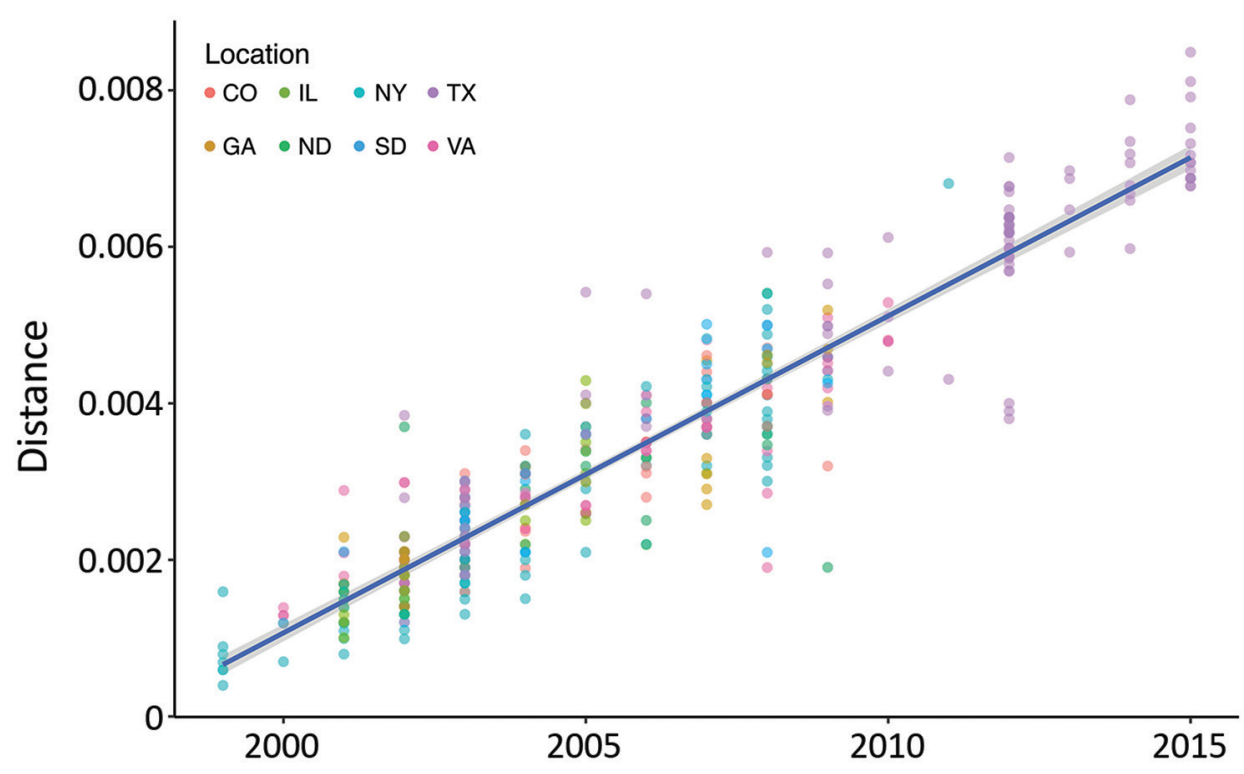

Figure 2. Analysis of correlation between virus isolation date and genetic diversity in study of terrestrial bird migration and West Nile virus circulation, United States. Root-to-tip distances of all sequences were determined for each isolate by using the maximumlikelihood tree shown in Figure 1 (https://wwwnc cdc.gov/EID/ article/24/12/18-0382-F1.htm) and plotted against the year. Dots are colored by location of isolation. The correlation between the root-to-tip distance and year of isolation was determined with linear regression shown in blue. $95 \%$ Cls are shown in gray. The equation of the linear regression line was used to estimate the year of the most recent common ancestor (MRCA) and the mutation rate $(m): y=m x+M R C A$. multiple independent MCMC chains until effective sample size values exceeded 200. Log and tree files were combined in LogCombiner version 1.8, and a maximum clade credibility tree was generated in TreeAnnotator (32). Locations were inferred by using ancestral state reconstruction with an asymmetric discrete trait substitution model (34).

\section{Analysis of Migration}

After the XML files were generated in BEAUti, we manually edited them to enable counting of all Markov jumps (MJ) (which described the relative magnitude of migration out of source locations and into sink locations) for 2001 through 2009 (35). This method for evaluating migration, first described by Minin and Suchard (35), has been used to characterize migration of several major pathogens including rabies virus (36), dengue virus (37), HIV (38), influenza virus $(39,40)$, and Rift Valley fever virus $(41)$.

As expected for an emerging zoonotic disease, the annual West Nile neurologic disease (WNND) incidence and sample collection efforts varied dramatically among states over time, adding substantial complexity to the model. To mitigate the effects of inconsistent sampling and to confirm the observed results, we applied a stricter inclusion criterion to confirm the results obtained by using the full dataset. The sequences were randomly down-sampled such that the number of sequences used correlated ( $<<0.05$ by Pearson method) with the incidence of WNND reported to the Centers for Disease Control and Prevention (CDC) in a particular year (the most accurate record of relative WNV activity). Our analysis ensured that the dataset was representative of the WNV activity of each region in a particular year.

We calculated incidence by using the number of WNND cases reported to CDC from each state during each year and dividing that number by the estimated population of each state. The population estimates were obtained from the Time Series of Intercensal State Population Estimates available at the Population Division of the US Census Bureau (42). States with insufficient sequences to represent the WNND incidence were excluded. Down-sampling was undertaken in at least duplicate to ensure that reduction in sample size and diversity did not remove important relationships.

\section{Results}

\section{Sequence Collection}

All previously published sequences of natural WNV isolates collected in the United States were obtained from GenBank on January 1, 2016. The number of WNV sequences varied substantially over time and among locations, which

\begin{tabular}{lccc}
\hline \multicolumn{3}{l}{ Table 3. Statistical support for phylogeny in study of terrestrial bird migration and West Nile virus circulation, United States } \\
\hline Variable & Mean & ESS & 95\% HPD interval \\
\hline Posterior & -49722.50 & 1370 & -49803.21 to -49640.55 \\
Prior & -3987.09 & 1110 & -4051.92 to -3916.56 \\
Likelihood & -45735.41 & 2179 & -45780.00 to -45691.43 \\
MRCA & 11.92 & 3119 & 10.82 to 13.08 \\
UCLD.mean & $3.92 \times 10^{-4}$ & 1604 & $3.55 \times 10^{-4}$ to $4.49 \times 10^{-4}$ \\
\hline
\end{tabular}

${ }^{*}$ ESS, effective sample size; HPD, highest posterior density; MRCA, most recent common ancestor (years before 2009); UCLD.mean, evolution rate inferred with an uncorrelated clock model with lognormal distribution. 
presented statistical challenges. In particular, although GenBank has $>900 \mathrm{WNV}$ open reading frames, most come from a few states where laboratories were actively involved in WNV surveillance and research: California, New York, and Texas. The ability to compare multiple isolates over

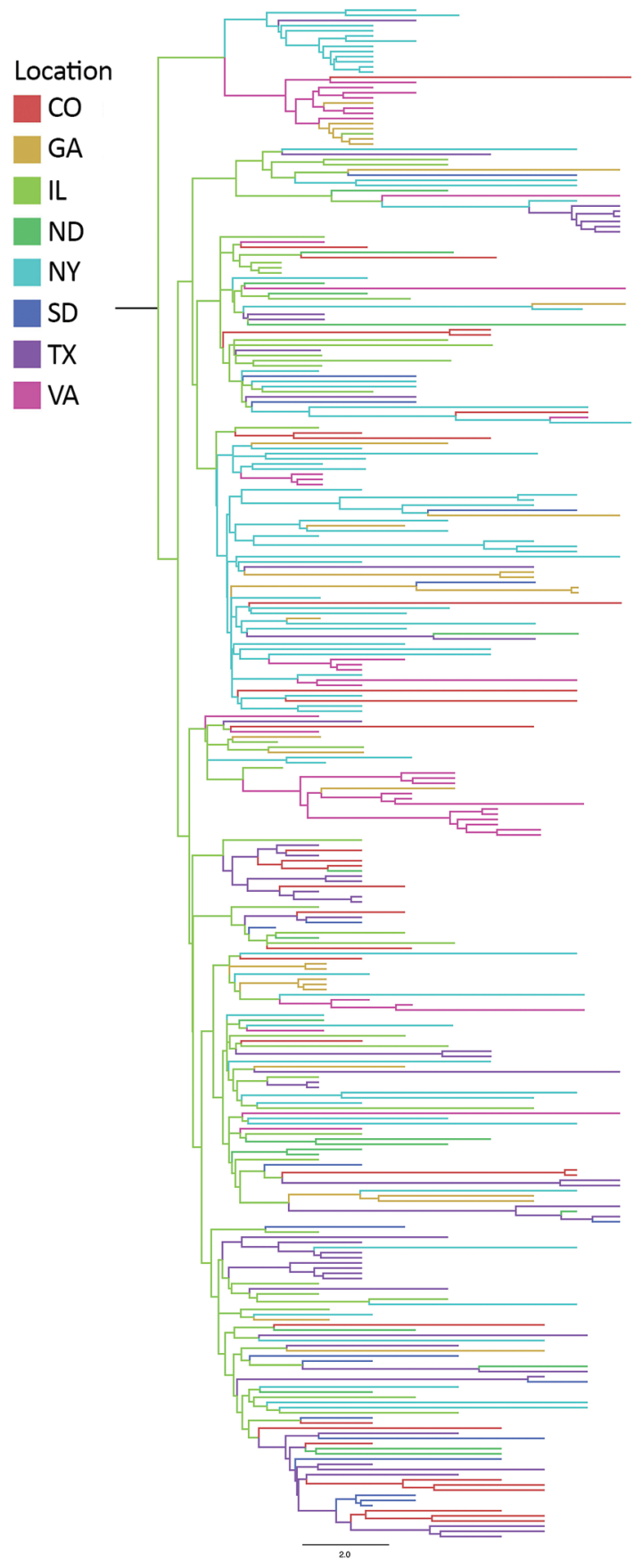

Figure 3. Bayesian phylogeny of West Nile virus isolates collected in representative regions along the Eastern and Central flyways between 2001 and 2009, United States. Maximum-clade credibility tree was obtained by using a Bayesian approach. The location of each isolate and the inferred location of each ancestor are depicted by color. multiple years was critical to the analysis. Only a few states had sufficient numbers of WNV sequences available in GenBank to enable analysis for multiple consecutive years: New York, Connecticut, Illinois, North Dakota, South Dakota, Texas, and California.

To mitigate the influence of sampling bias, we obtained additional WNV isolates from the World Reference Center for Emerging Viruses and Arboviruses for 3 states and sequences to support the analysis: Virginia (n =39), Georgia $(\mathrm{n}=20)$, and Colorado $(\mathrm{n}=31)$ (Table 1, https://wwwnc.cdc.gov/EID/article/24/12/18-0382-T1. $\mathrm{htm})$. Given that previous studies have demonstrated limited WNV movement into or out of California $(6,7)$, we did not include isolates from California in the analysis. Similarly, because of the proximity of New York and Connecticut, we chose New York to represent WNV in the Northeast because Connecticut is a small state. Last, to ensure that each location was represented across a similar time frame, we included only isolates collected during 2001-2009 in the Bayesian phylogeny and migration analysis. Table 2 shows the states and availability of yearly isolates.

\section{Model Selection}

We compared 203 nucleotide substitution models by using the Bayesian and Akaike Information Criteria in JModelTest2 (https://github/com/ddariba/jmodeltest2) and found the GTR $+\Gamma+\mathrm{I}$ model to be the most appropriate. For assessing temporal signature, we used a maximum-likelihood tree with sequences of WNV strains from New York, Virginia, Georgia, Illinois, North Dakota, South Dakota, Texas, and Colorado $(\mathrm{n}=379)$ (Figure 1, https://wwwnc.cdc.gov/EID/ article/24/12/18-0382-F1.htm). We identified a statistically significant positive correlation $(\mathrm{r}=0.93,95 \%$ highest posterior density $\left.[\mathrm{HPD}]=0.92-0.94 ; \mathrm{p}<2.2 \times 10^{-16}\right)$ between the root-to-tip distance and the date of isolation in Temp-Est (formerly known as Path-O-gen) (Figure 2). The mutation rate was estimated to be $4.05 \times 10^{-4}$ substitutions/site/year, and the most recent common ancestor (MRCA) was in 1997. Together these results indicated a strong temporal signal in the dataset. Finally, we evaluated Bayesian tree priors (skyride, skygrid, and skyline) and uncorrelated clock models (lognormal and exponential) by using path-sampling and steppingstone approaches. The uncorrelated lognormal clock model with the Bayesian skyline tree prior was the most appropriate.

\section{Phylogeographic Analysis for the United States}

Analysis of all WNV sequences collected from New York, Virginia, Georgia, Illinois, North Dakota, South Dakota, Texas, and Colorado during 2001-2009 provided estimates of the introduction date of the MRCA and mean evolution rate that were consistent with the estimates of the root-totip distance analysis (Table 3; Figure 3, https://wwwnc. cdc.gov/EID/article/24/12/18-0382-F3.htm). The date of 
Terrestrial Bird Migration and West Nile Virus

Table 4. Source and sink analysis in study of terrestrial bird migration and West Nile virus circulation, United States*

\begin{tabular}{|c|c|c|c|c|}
\hline Source & Sink & Markov jumps, mean & ESS & 95\% HPD interval \\
\hline $\mathrm{CO}$ & ND & 1.368 & 8603 & $0-3$ \\
\hline GA & IL & 1.31 & 31284 & $1-3$ \\
\hline IL & $\mathrm{CO}$ & 8.376 & 3311 & $1-14$ \\
\hline IL & GA & 8.226 & 3046 & $3-13$ \\
\hline IL & ND & 10.43 & 15423 & $6-14$ \\
\hline IL & NY & 29.965 & 1355 & $20-40$ \\
\hline IL & SD & 6.691 & 3635 & $1-11$ \\
\hline IL & $\mathrm{TX}$ & 22.872 & 4545 & $14-30$ \\
\hline IL & VA & 11.449 & 1631 & $6-16$ \\
\hline NY & $\mathrm{CO}$ & 4.362 & 2143 & $0-8$ \\
\hline NY & GA & 7.039 & 2170 & $2-11$ \\
\hline NY & IL & 1.012 & 3023 & $0-4$ \\
\hline NY & SD & 2.177 & 2740 & $0-5$ \\
\hline NY & TX & 4.564 & 2149 & $0-9$ \\
\hline NY & VA & 4.24 & 1171 & $0-8$ \\
\hline SD & $\mathrm{CO}$ & 1.328 & 3964 & $0-5$ \\
\hline $\mathrm{TX}$ & $\mathrm{CO}$ & 9.775 & 6039 & $3-16$ \\
\hline $\mathrm{TX}$ & ND & 5.177 & 7617 & $2-9$ \\
\hline $\mathrm{TX}$ & NY & 1.606 & 9410 & $0-4$ \\
\hline $\mathrm{TX}$ & SD & 7.557 & 5113 & $2-12$ \\
\hline VA & $\mathrm{CO}$ & 1.16 & 9807 & $0-3$ \\
\hline VA & GA & 3.616 & 14054 & $2-6$ \\
\hline
\end{tabular}

MRCA introduction was estimated as 1997 , and the average evolution rate was $3.92 \times 10^{-4}$ substitutions/site/year.

We used MJ between reconstructed ancestral states to estimate the magnitude of relative migration out of, or into, each of the 8 regions (Table 4; Table 5, https:// wwwnc.cdc.gov/EID/article/24/12/18-0382-T5.htm). Frequent migration $(>2 \mathrm{MJ}$ ) was detected from Illinois to Colorado (8.38 MJ), Illinois to Georgia (8.23 MJ), Illinois to North Dakota (10.43 MJ), Illinois to New York (29.97 MJ), Illinois to South Dakota (6.69 MJ), Illinois to Texas $(22.87 \mathrm{MJ})$, Illinois to Virginia (11.45 MJ), New York to Colorado (4.36 MJ), New York to Georgia (7.04 MJ), New York to South Dakota (2.18 MJ), New York to Texas (4.56 MJ), New York to Virginia (4.24 MJ), Texas to Colorado (9.78 MJ), Texas to North Dakota (5.18 MJ), Texas to South Dakota (7.56 MJ), and Virginia to Georgia (3.62 MJ).

Overall, 3 major sources of WNV circulation (New York, Illinois, and Texas) seemed to be the origin of $88.5 \%$ of the total migration events observed (Table 4; Figure 4). Southward and westward movements were detected along the East Coast, but only northward movement was observed within the central United States. A notable exception was observed in Illinois, where evidence of WNV movement in all directions was demonstrated.

\section{Incidence-Controlled Phylogeny}

To mitigate the effects of inconsistent sampling, we applied a stricter inclusion criterion to ensure that the dataset was representative of WNV activity in each region in a particular year. In this approach, the sequences were randomly down-sampled by using the sample command in R, such that the number of sequences was proportional to the incidence of WNND reported to CDC (Table 6). Illinois, North Dakota, and South Dakota were not included in the downsampled datasets because there were insufficient sequences to represent WNND incidence in these states. To ensure that reduction in sample size and diversity did not remove
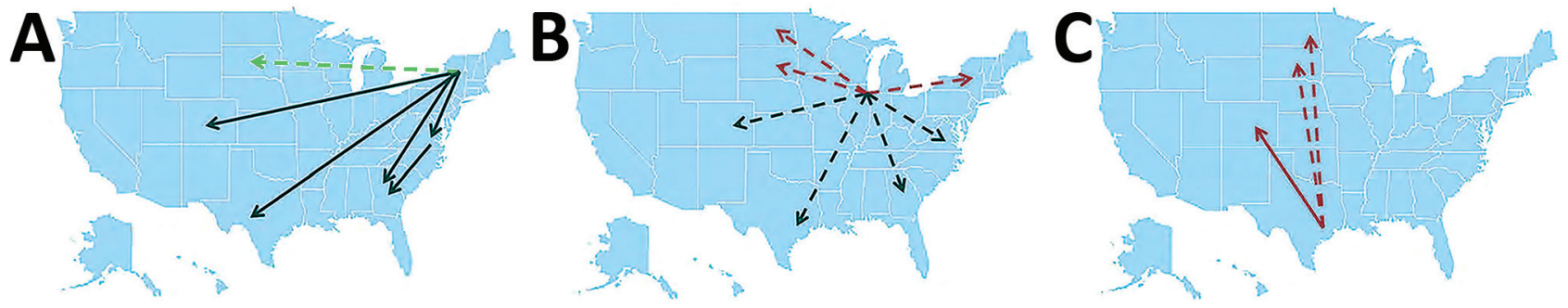

Figure 4. Summary of source/sink analysis in study of terrestrial bird migration and West Nile virus circulation, United States. Minimum number of migration events detected from A) the Eastern flyway, B) Illinois, and C) the Central flyway. Only events that occurred at least twice are depicted. Red arrows, northward migration; black arrows, southward migration; green arrow, lateral migration; dotted arrows, migration that could not be confirmed by incident-controlled down sampling because of an insufficient number of sequences. 
Table 6. Incidence-controlled down-sampling strategy used in study of of terrestrial bird migration and WNV circulation, United States*

\begin{tabular}{|c|c|c|c|}
\hline Location, year & WNV incidence & Sequences available & Sequences used \\
\hline \multicolumn{4}{|l|}{ GA } \\
\hline 2001 & $7.16 \times 10^{-7}$ & 5 & 3 \\
\hline 2002 & $3.29 \times 10^{-6}$ & 11 & 6 \\
\hline 2003 & $3.13 \times 10^{-6}$ & 1 & 1 \\
\hline 2004 & $1.60 \times 10^{-6}$ & 2 & 2 \\
\hline 2005 & $1.01 \times 10^{-6}$ & 1 & 1 \\
\hline 2006 & $2.18 \times 10^{-7}$ & 0 & 0 \\
\hline 2007 & $2.46 \times 10^{-6}$ & 5 & 5 \\
\hline 2008 & $4.21 \times 10^{-7}$ & 3 & 3 \\
\hline 2009 & $4.16 \times 10^{-7}$ & 3 & 3 \\
\hline \multicolumn{4}{|l|}{ NY } \\
\hline 2001 & $6.81 \times 10^{-7}$ & 10 & 3 \\
\hline 2002 & $3.55 \times 10^{-6}$ & 10 & 6 \\
\hline 2003 & $2.97 \times 10^{-6}$ & 15 & 5 \\
\hline 2004 & $3.65 \times 10^{-7}$ & 10 & 3 \\
\hline 2005 & $1.57 \times 10^{-6}$ & 7 & 4 \\
\hline 2006 & $8.37 \times 10^{-7}$ & 5 & 3 \\
\hline 2007 & $8.36 \times 10^{-7}$ & 9 & 3 \\
\hline 2008 & $1.67 \times 10^{-6}$ & 18 & 4 \\
\hline 2009 & $3.11 \times 10^{-7}$ & 2 & 2 \\
\hline \multicolumn{4}{|l|}{ VA } \\
\hline 2001 & 0 & 6 & 2 \\
\hline 2002 & $2.20 \times 10^{-6}$ & 10 & 5 \\
\hline 2003 & $2.58 \times 10^{-6}$ & 6 & 5 \\
\hline 2004 & $6.69 \times 10^{-7}$ & 4 & 3 \\
\hline 2005 & 0 & 3 & 2 \\
\hline 2006 & 0 & 4 & 2 \\
\hline 2007 & $3.87 \times 10^{-7}$ & 2 & 2 \\
\hline 2008 & 0 & 4 & 2 \\
\hline 2009 & $6.31 \times 10^{-7}$ & 5 & 3 \\
\hline
\end{tabular}

important relationships, the down-sampling was independently performed twice.

According to the 2 incidence-controlled datasets, the MRCA was $\approx 1997$ in both down-sampling exercises (95\% HPD 1996.001998 .52 and 95\% HPD 1995.7 1998.25), and the overall mutation rates were estimated to be $4.02 \times$ $10^{-4}$ and $3.83 \times 10^{-4}$ substitutions/site/year (Table 7; Figure 5, https://wwwnc.cdc.gov/EID/article/24/12/18-0382-F5. $\mathrm{htm})$. As with the full dataset, the Markov analysis demonstrated that New York and Texas were strong sources of WNV circulation. Significant movement (mean $>2 \mathrm{MJ}$ ) was detected from Texas to Colorado (20.42 and 20.44 MJ); Texas to New York (12.36 and 11.77 MJ); Texas to Georgia (8.28 and 9.55 MJ); Texas to Virginia (7.14 and 7.732 MJ); New York to Georgia (6.1 and 5.38 MJ); New York to Virginia (4.95 and 3.65 MJ); New York to Colorado
(4.04 and 2.66 MJ); New York to Texas (2.66 and 2.73 $\mathrm{MJ}$ ); Virginia to Georgia (1.55 and 3.62 MJ); and, in dataset 2 only, Virginia to Colorado (1.31 MJ) (Figure 6).

Together, the MJ analyses of the incidence-controlled dataset and the full dataset illustrate a consistent pattern of WNV circulation. All southward movement originated in the eastern United States (New York and Virginia), and most of the northward movement originated in the central United States (Texas) (Figure 7).

\section{Discussion}

In recent years, emerging zoonotic diseases caused by Ebola, Zika, Nipah, Middle Eastern respiratory syndrome, and influenza A viruses have become major public health problems, devastating communities and costing millions for public health interventions. Decisive,

Table 7. Statistical support for the incidence-controlled phylogenies determined in study of terrestrial bird migration and West Nile virus circulation, United States*

\begin{tabular}{lcccccc}
\hline & \multicolumn{2}{c}{ Dataset 1 } & \multicolumn{2}{c}{ Dataset 2 } \\
\cline { 2 - 7 } Variable & Mean & ESS & $95 \%$ HPD interval & Mean & ESS & 95\% HPD interval \\
\cline { 2 - 7 } Posterior & -36338.60 & 1385 & -36394.36 to -36280.37 & -36798.90 & 1803 & -36853.19 to -36740.97 \\
Prior & -3141.96 & 1187 & -3189.54 to -3091.38 & -3153.08 & 1387 & -3201.84 to -3104.50 \\
Likelihood & -33196.64 & 1367 & -33229.23 to -33165.79 & -33645.82 & 2115 & -33678.80 to -33614.39 \\
MRCA & 11.66 & 4720 & 10.47 to 12.10 & 11.97 & 6985 & 10.75 to 13.30 \\
UCLD.mean & $4.02 \times 10^{-4}$ & 2336 & $3.53 \times 10^{-4}$ to $4.55 \times 10^{-4}$ & $3.83 \times 10^{-4}$ & 1749 & $3.31 \times 10^{-4}$ to $4.39 \times 10^{-4}$ \\
\hline
\end{tabular}

${ }^{\star}$ ESS, effective sample size; HPD, highest posterior density; MRCA, most recent common ancestor (years before 2009); UCLD.mean, evolution rate inferred with an uncorrelated clock model with lognormal distribution. 

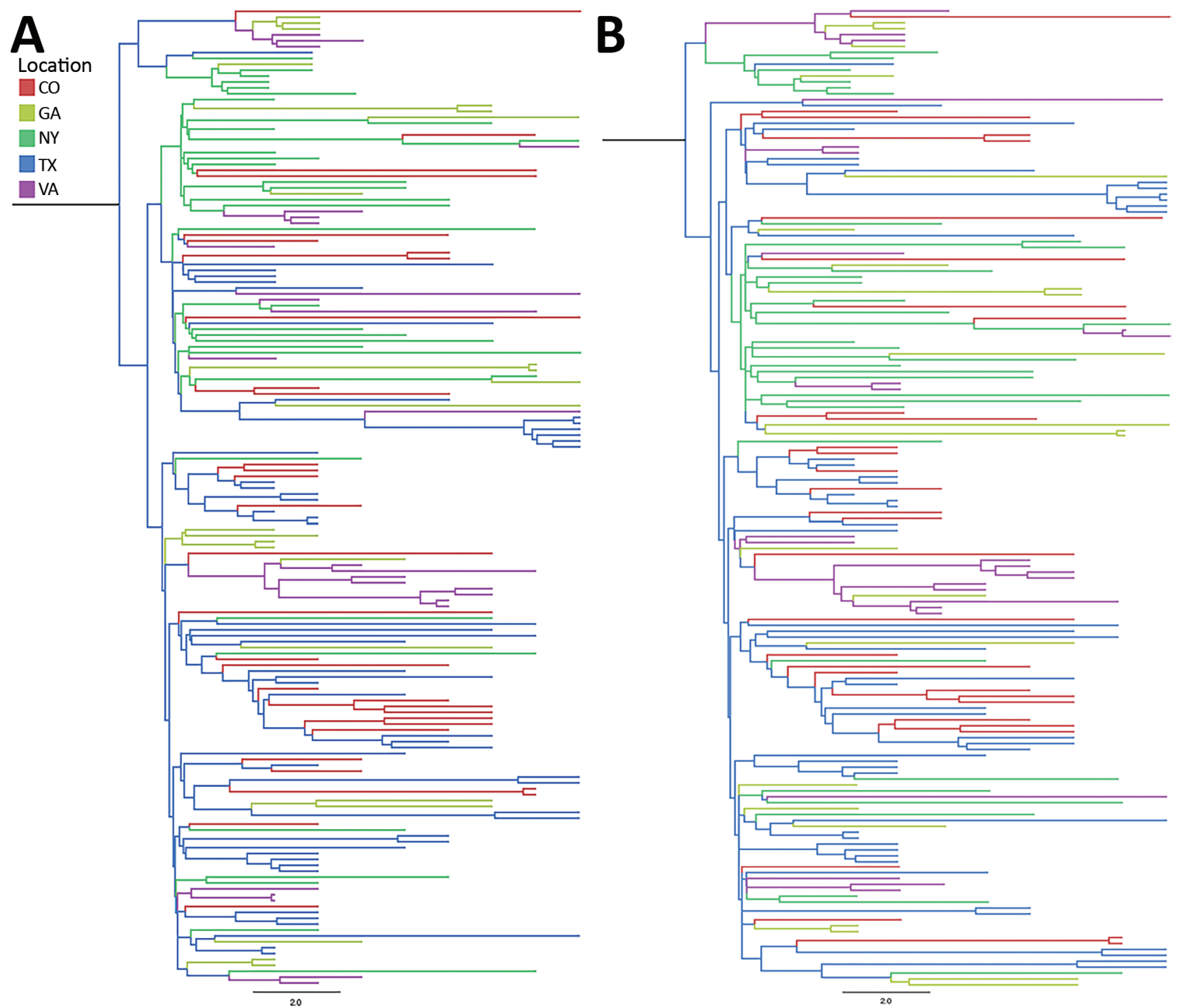

Figure 5. Incidence-controlled phylogeny of Eastern and Central flyways, United States. Sequences were down-sampled such that the number of sequences was proportional to the annual incidence of West Nile neurologic disease incidence for each location between 2001 and 2009. Down-sampling was undertaken twice ( $A$ and $B$ ) to ensure that the reduction in sequences did not result in a substantial loss of diversity. Illinois, North Dakota, and South Dakota were not included in the incidence-control analysis because too few sequences were available to support down-sampling. Bayesian approaches were used to generate maximum-clade credibility trees. Scale bars indicate nucleotide substitutions per site.

evidence-based approaches are critical for managing emerging infectious diseases, but effective and efficient countermeasures will be possible only after the relationships between pathogens and their hosts have been thoroughly characterized.

Bird migration has been implicated in the movement of a variety of pathogens (1). In particular, characterization of the relationship between avian influenza virus movement and waterfowl migration has supported surveillance and early warning programs $(1,43)$. However, studies of avian hosts in the Americas have mainly concentrated on the migration of waterfowl to the exclusion of terrestrial birds because waterfowl are easily tracked with banding; thus, their migration has been thoroughly characterized.

The introduction and subsequent spread of WNV into the Americas underscores the invasive potential of emerging pathogens in the New World, as has been recently exemplified by Zika virus, another mosquitoborne flavivirus. Dramatic variations in the location, timing, and intensity of WNV strain collection and sequencing has left the field with a limited understanding of virus circulation patterns and no reliable way of predicting the geographic spread of WNV outbreaks. We have addressed this knowledge gap 
A

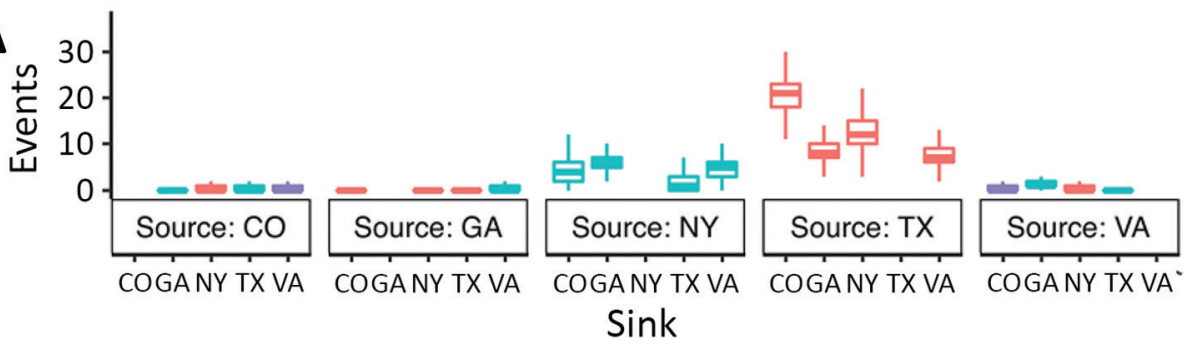

B
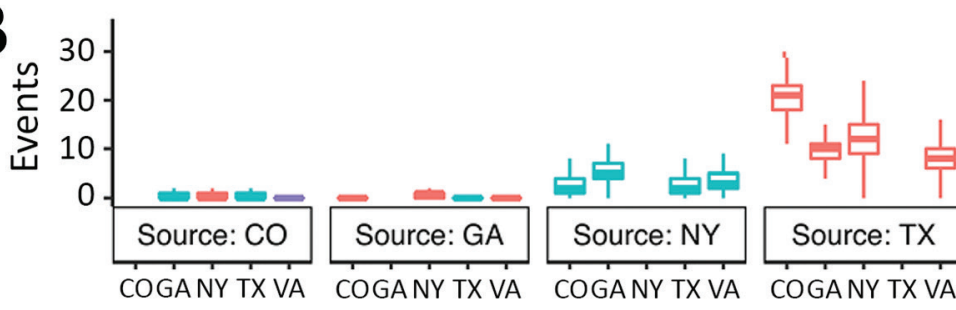

COGANYTXVA Sink

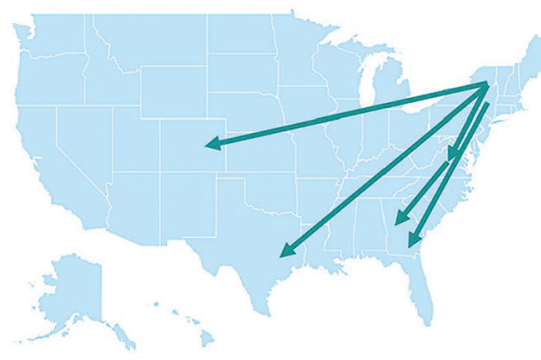

D

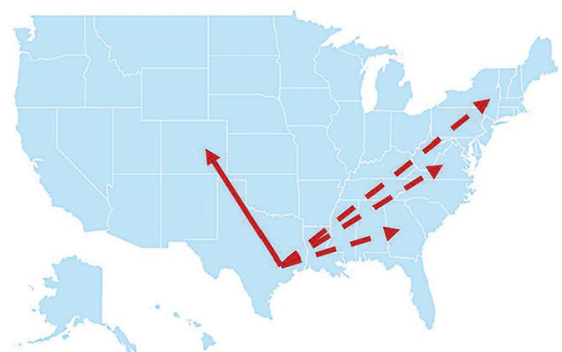

Figure 6. Summary of Markov jump analysis performed on the incidentcontrolled phylogeny. A, B) The results of the Markov jump analysis for each down-sampled dataset are summarized as box plots. Box tops indicate third quartiles, box bottoms indicate first quartiles; horizontal bars within boxes indicate medians; error bars indicate maximums and minimums. Red, northward movement; teal, southward movement; purple, movement that is neither north nor south; dotted arrows, movement that was not observed in the incident-controlled down-sampling because of an insufficient number of sequences. C, D) Movement originating in the eastern and central United States. Only Markov jumps that occurred $\geq 2$ times are depicted. by characterizing the movement of WNV with regard to the migratory patterns of its natural hosts, terrestrial birds. We compiled 379 virus sequences for analysis, including 289 previously reported sequences from New York, Virginia, Georgia, Illinois, North Dakota, South Dakota, Texas, and Colorado, plus 90 novel sequences from Virginia, Georgia, and Colorado.

Phylogeographic analysis revealed that 3 locationsNew York, Illinois, and Texas - accounted for $88.5 \%$ of the total WNV MJ inferred. Because New York is the presumed original introduction point for WNV into the United States, its role as a major source of WNV movement was expected. However, $74.2 \%$ of the observed MJ originated in Illinois and Texas only. Of note, North Dakota and South Dakota, which are 2 of the states with the highest annual WNND incidence, seem to be strong sinks for WNV moving out of Illinois and Texas.

The contributions of Illinois and Texas to WNV circulation are not surprising because both locations are situated at major convergence points between the Eastern and Central flyways. In the case of Texas, birds from both flyways may avoid long-distance flights across the Gulf of Mexico by traveling along the circa-Gulf route that follows the Gulf Coast through Texas into Mexico. In the case of Illinois, seasonal shifts in terrestrial bird migration routes ensure that Illinois supports birds from the Eastern and Central flyways during annual migrations.

Of note, although mosquito and WNV activity occurs earlier in the southern than in the northern United States, southward migration was detected along the East Coast during our sampling period, 2002-2009, indicating that the southeastern United States is probably a dead end for WNV circulation. Indeed, low-level transmission probably occurs during the winter in warmer locations such as Florida, Texas, and Louisiana. This possibility is supported by isolations of WNV from mosquitoes and birds during December and January in Harris County, Texas (44), and suggests that ecologic factors not related to mosquito abundance and WNV activity drive WNV movement along the East Coast. Instead, movement of WNV into the northeastern United States (New York) from Illinois and Texas was observed (in the incident-controlled analysis). These results suggest that introduction of WNV into the northeastern United States originated from the central United States.

Overall, we have defined the pattern of WNV circulation in the United States (Figure 7) and demonstrated looped virus movement patterns in the Eastern and Central flyways that are bridged by Illinois, a region shared between the 


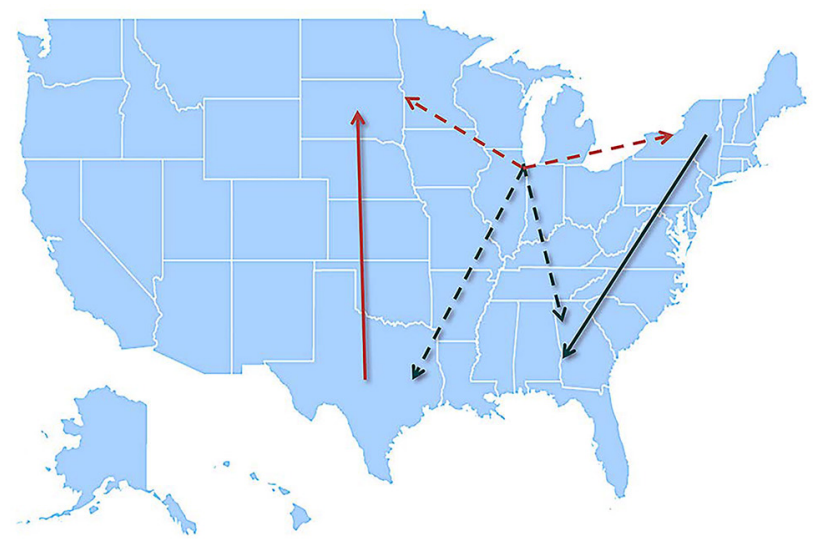

Figure 7. Model summarizing the general patterns of West Nile virus movement in the United States. Red, northward movement; teal, southward movement; dotted arrows, relationships that could not be confirmed in incident-controlled datasets because of an insufficient number of sequences.

2 flyways. This specific pattern correlates with the looped migration patterns of terrestrial birds. Although other geographic regions may contribute to virus movement, there were insufficient virus sequences available from other states to incorporate into this analysis. Thus, on the basis of available information, 3 of the 8 locations considered (New York, Illinois, and Texas) seem to be the preferred sites for efficiently monitoring ongoing WNV evolution.

As new WNV sequences become available, similar phylogeographic methods can be used to develop more detailed information about WNV circulation in the United States. For example, on the East Coast, WNV circulation occurs southward, so surveillance efforts in the Northeast are likely to be more informative than surveillance in the Southeast. Conversely, WNV in the central United States travels northward, so surveillance in the south-central United States is more likely than surveillance in the northcentral United States to be informative. Last, the region of overlap between the Eastern and Central flyways is the most likely location for deriving surveillance information because WNV in this area travels in multiple directions.

Collectively, the results of this study illustrate the value of using multidisciplinary approaches to surveillance of infectious diseases, especially zoonotic diseases. Animal migration is shaped by a delicate balance of ecologic factors and anthropomorphic barriers. Natural and manmade events (e.g., climate change, atmospheric fluctuations, habitat destruction) can drastically alter host behavior, which in turn affects the circulation patterns of infectious agents such as WNV. In this study, we defined the patterns of WNV circulation and key areas for surveillance and correlated them with the migratory patterns of their primary reservoir, terrestrial birds. Although this information does not enable prediction of the size of annual WNV outbreaks, these advancements support the construction of targeted surveillance and vector mitigation strategies to predict the annual flow of WNV strains and to enable public health officials to anticipate changes in WNV circulation resulting from altered bird migration.

This study was supported in part by National Institutes of Health contracts N01-AI 25489, N01-AI30027, and HHSN272201000040I/HHSN27200004/D04 to R.B.T. and grant AI 067847 to A.D.T.B.

\section{About the Author}

Dr. Swetnam is a postdoctoral fellow at the University of California at Davis. Her research interests include the evolution and molecular epidemiology of zoonotic and emerging diseases.

\section{References}

1. Reed KD, Meece JK, Henkel JS, Shukla SK. Birds, migration and emerging zoonoses: West Nile virus, lyme disease, influenza A and enteropathogens. Clin Med Res. 2003;1:5-12. http://dx.doi.org/10.3121/cmr.1.1.5

2. Pybus OG, Suchard MA, Lemey P, Bernardin FJ, Rambaut A, Crawford FW, et al. Unifying the spatial epidemiology and molecular evolution of emerging epidemics. Proc Natl Acad Sci U S A. 2012;109:15066-71. http://dx.doi.org/10.1073/ pnas. 1206598109

3. Lewis M, Rencławowicz J, van den Driessche P. Traveling waves and spread rates for a West Nile virus model. Bull Math Biol. 2006;68:3-23. http://dx.doi.org/10.1007/s11538-005-9018-z

4. Maidana NA, Yang HM. Spatial spreading of West Nile Virus described by traveling waves. J Theor Biol. 2009;258:403-17. http://dx.doi.org/10.1016/j.jtbi.2008.12.032

5. Duggal NK, Reisen WK, Fang Y, Newman RM, Yang X, Ebel GD, et al. Genotype-specific variation in West Nile virus dispersal in California. Virology. 2015;485:79-85. http://dx.doi.org/10.1016/ j.virol.2015.07.004

6. Duggal NK, Bosco-Lauth A, Bowen RA, Wheeler SS, Reisen WK, Felix TA, et al. Evidence for co-evolution of West Nile Virus and house sparrows in North America. PLoS Negl Trop Dis. 2014;8:e3262. http://dx.doi.org/10.1371/journal.pntd.0003262

7. Añez G, Grinev A, Chancey C, Ball C, Akolkar N, Land KJ, et al. Evolutionary dynamics of West Nile virus in the United States, 1999-2011: phylogeny, selection pressure and evolutionary time-scale analysis [cited 2013 Dec 13]. http://dx.plos.org/10.1371/ journal.pntd.0002245

8. Formosinho P, Santos-Silva MM. Experimental infection of Hyalomma marginatum ticks with West Nile virus. Acta Virol. 2006; 50:175-80.

9. Komar N, Langevin S, Hinten S, Nemeth N, Edwards E, Hettler D, et al. Experimental infection of North American birds with the New York 1999 strain of West Nile virus. Emerg Infect Dis. 2003;9:311-22. http://dx.doi.org/10.3201/eid0903.020628

10. Wheeler SS, Langevin SA, Brault AC, Woods L, Carroll BD, Reisen WK. Detection of persistent West Nile virus RNA in experimentally and naturally infected avian hosts. Am J Trop Med Hyg. 2012;87:559-64. http://dx.doi.org/10.4269/ ajtmh.2012.11-0654

11. Bakonyi T, Gajdon GK, Schwing R, Vogl W, Häbich AC, Thaller D, et al. Chronic West Nile virus infection in kea (Nestor notabilis). Vet Microbiol. 2016;183:135-9. http://dx.doi.org/10.1016/j.vetmic.2015.12.012 
12. Di Giallonardo F, Geoghegan JL, Docherty DE, McLean RG, Zody MC, Qu J, et al. Fluid spatial dynamics of West Nile virus in the United States: rapid spread in a permissive host environment. J Virol. 2015;90:862-72. http://dx.doi.org/10.1128/JVI.02305-15

13. Bahl J, Krauss S, Kühnert D, Fourment M, Raven G, Pryor SP, et al. Influenza a virus migration and persistence in North American wild birds. PLoS Pathog. 2013;9:e1003570. http://dx.doi.org/10.1371/journal.ppat.1003570

14. Vollmer SA, Bormane A, Dinnis RE, Seelig F, Dobson ADM, Aanensen DM, et al. Host migration impacts on the phylogeography of Lyme borreliosis spirochaete species in Europe. Environ Microbiol. 2011;13:184-92. http://dx.doi.org/10.1111/ j.1462-2920.2010.02319.x

15. Muñoz J, Amat F, Green AJ, Figuerola J, Gómez A. Bird migratory flyways influence the phylogeography of the invasive brine shrimp Artemia franciscana in its native American range. PeerJ. 2013;1:e200. http://dx.doi.org/10.7717/peerj.200

16. Dusek RJ, McLean RG, Kramer LD, Ubico SR, Dupuis AP II, Ebel GD, et al. Prevalence of West Nile virus in migratory birds during spring and fall migration. Am J Trop Med Hyg. 2009;81:1151-8. http://dx.doi.org/10.4269/ajtmh.2009.09-0106

17. Reisen WK, Wheeler SS, Garcia S, Fang Y. Migratory birds and the dispersal of arboviruses in California. Am J Trop Med Hyg. 2010;83:808-15. http://dx.doi.org/10.4269/ajtmh.2010.10-0200

18. La Sorte FA, Fink D, Hochachka WM, Farnsworth A, Rodewald AD, Rosenberg KV, et al. The role of atmospheric conditions in the seasonal dynamics of North American migration flyways. J Biogeogr. 2014;41:1685-96. http://dx.doi.org/10.1111/jbi.12328

19. La Sorte FA, Fink D, Hochachka WM, DeLong JP, Kelling S. Spring phenology of ecological productivity contributes to the use of looped migration strategies by birds. Proc Biol Sci. 2014;281:20140984-20140984. http://dx.doi.org/10.1098/ rspb.2014.0984

20. Phillips AR. Migrations of Allen's and other hummingbirds. Condor. 1975;77:196-205. http://dx.doi.org/10.2307/1365790

21. Klaassen RHG, Strandberg R, Hake M, Olofsson P, Tøttrup AP, Alerstam T. Loop migration in adult marsh harriers Circus aeruginosus, as revealed by satellite telemetry. J Avian Biol. 2010; 41:200-7. http://dx.doi.org/10.1111/j.1600-048X.2010.05058.x

22. Mellone U, López-López P, Limiñana R, Piasevoli G, Urios V. The trans-equatorial loop migration system of Eleonora's falcon: differences in migration patterns between age classes, regions and seasons. J Avian Biol. 2013;44 [cited 2018 Oct 5]. http://doi.wiley.com/10.1111/j.1600-048X.2013.00139.x

23. Willemoes M, Strandberg R, Klaassen RHG, Tøttrup AP, Vardanis Y, Howey PW, et al. Narrow-front loop migration in a population of the common cuckoo Cuculus canorus, as revealed by satellite telemetry. PLoS One. 2014;9:e83515. http://dx.doi.org/ 10.1371/journal.pone.0083515

24. Boere GC, Stroud DA. The flyway concept: what it is and what it isn't. In: Boere GC, Galbraith C., Stroud DA, editors. Waterbirds around the World. Edinburgh: The Stationery Office; 2006. p. 40-4.

25. Hatcher EL, Zhdanov SA, Bao Y, Blinkova O, Nawrocki EP, Ostapchuck Y, et al. Virus Variation Resource-improved response to emergent viral outbreaks. Nucleic Acids Res. 2017;45:D482-90. http://dx.doi.org/10.1093/nar/gkw1065

26. Health UTMB. World Reference Center for Emerging Viruses and Arboviruses [cited 2018 Feb 20]. https://www.utmb.edu/wrceva/ home

27. Bolger AM, Lohse M, Usadel B. Trimmomatic: a flexible trimmer for Illumina sequence data. Bioinformatics. 2014;30:2114-20. http://dx.doi.org/10.1093/bioinformatics/btu170

28. Langmead B, Salzberg SL. Fast gapped-read alignment with Bowtie 2 [cited 2014 Mar 19]. http://www.central.nih.gov/ articlerender.fcgi? artid $=3322381 \&$ tool $=$ pmcentrez\&rendertype $=$ abstract
29. Li H, Handsaker B, Wysoker A, Fennell T, Ruan J, Homer N, et al. 1000 Genome Project Data Processing Subgroup. The Sequence Alignment/Map format and SAMtools. Bioinformatics. 2009;25:2078-9. http://dx.doi.org/10.1093/bioinformatics/btp352

30. Miller MA, Pfeiffer W, Schwartz T. Creating the CIPRES Science Gateway for inference of large phylogenetic trees [cited 2018 Oct 5]. http://ieeexplore.ieee.org/document/5676129/

31. Rambaut A, Lam TT, Max Carvalho L, Pybus OG. Exploring the temporal structure of heterochronous sequences using TempEst (formerly Path-O-Gen) [cited 2018 Oct 5]. http://ve.oxfordjournals.org/lookup/doi/10.1093/ve/vew007

32. Drummond AJ, Suchard MA, Xie D, Rambaut A. Bayesian phylogenetics with BEAUti and the BEAST 1.7. Mol Biol Evol. 2012;29:1969-73. http://dx.doi.org/10.1093/molbev/mss075

33. Gray RR, Veras NMC, Santos LA, Salemi M. Evolutionary characterization of the West Nile virus complete genome. Mol Phylogenet Evol. 2010;56:195-200. http://dx.doi.org/10.1016/ j.ympev.2010.01.019

34. Lemey P, Rambaut A, Drummond AJ, Suchard MA. Bayesian phylogeography finds its roots. PLOS Comput Biol. 2009;5:e1000520. http://dx.doi.org/10.1371/journal.pcbi.1000520

35. Minin VN, Suchard MA. Counting labeled transitions in continuous-time Markov models of evolution. J Math Biol. 2008;56:391-412. http://dx.doi.org/10.1007/s00285-007-0120-8

36. Tohma K, Saito M, Kamigaki T, Tuason LT, Demetria CS, Orbina JRC, et al. Phylogeographic analysis of rabies viruses in the Philippines. Infect Genet Evol. 2014;23:86-94. http://dx.doi.org/10.1016/j.meegid.2014.01.026

37. Raghwani J, Rambaut A, Holmes EC, Hang VT, Hien TT, Farrar J, et al. Endemic dengue associated with the co-circulation of multiple viral lineages and localized density-dependent transmission. PLoS Pathog. 2011;7:e1002064. http://dx.doi.org/ 10.1371/journal.ppat.1002064

38. Ward MJ, Lycett SJ, Kalish ML, Rambaut A, Leigh Brown AJ. Estimating the rate of intersubtype recombination in early HIV-1 group M strains. J Virol. 2013;87:1967-73. http://dx.doi.org/10.1128/JVI.02478-12

39. Lemey P, Rambaut A, Bedford T, Faria N, Bielejec F, Baele G, et al. Unifying viral genetics and human transportation data to predict the global transmission dynamics of human influenza H3N2. PLoS Pathog. 2014;10:e1003932. http://dx.doi.org/10.1371/ journal.ppat. 1003932

40. Nelson MI, Viboud C, Vincent AL, Culhane MR, Detmer SE, Wentworth DE, et al. Global migration of influenza A viruses in swine. Nat Commun. 2015;6:6696. http://dx.doi.org/10.1038/ ncomms 7696

41. Samy AM, Peterson AT, Hall M. Phylogeography of Rift Valley fever virus in Africa and the Arabian Peninsula. PLoS Negl Trop Dis. 2017;11:e0005226. http://dx.doi.org/10.1371/ journal.pntd.0005226

42. US Census Bureau. State intercensal tables: 2000-2010 [cited 2018 Oct 3]. https://www.census.gov/data/tables/time-series/demo/ popest/intercensal-2000-2010-state. html

43. Global Consortium for H5N8 and Related Influenza Viruses. Role for migratory wild birds in the global spread of avian influenza H5N8. Science. 2016;354:213-7. http://dx.doi.org/ $10.1126 /$ science.aaf8852

44. Tesh RB, Parsons R, Siirin M, Randle Y, Sargent C, Guzman H, et al. Year-round West Nile virus activity, Gulf Coast region, Texas and Louisiana. Emerg Infect Dis. 2004;10:1649-52. http://dx.doi.org/10.3201/eid1009.040203

Address for correspondence: Alan D.T. Barrett, University of Texas Medical Branch, 301 University Blvd, Galveston, TX 77555-0436, USA; email: abarrett@utmb.edu 